\title{
Identification Model for Determining Mathematical Sentences as Valid Argument
}

\author{
Nonik Indrawatiningsih ${ }^{1,2}$, Purwanto ${ }^{1, *}$, Abdur Rahman As'ari ${ }^{1}$, Cholis Sa'dijah ${ }^{1}$, Dwiyana ${ }^{1}$, \\ Luthfi Hakim $^{3}$

\begin{abstract}
${ }^{1}$ Mathematics Education, FMIPA State University of Malang, Jl. Semarang No. 5, Malang, Indonesia
${ }^{3}$ Mechanical Engineering, Majapahit Islamic University, Jl. Jabon km 07, Mojokerto, Indonesia ${ }^{*}$ Corresponding Author: purwanto.fmipa@um.ac.id
\end{abstract} \\ ${ }^{2}$ Mathematics Education, STKIP PGRI Pasuruan, Jl. Ki Hajar Dewantara No. 27-29, Pasuruan, Indonesia
}

Copyright@2019 by authors, all rights reserved. Authors agree that this article remains permanently open access under the terms of the Creative Commons Attribution License 4.0 International License

\begin{abstract}
Argument skills are one of the most fundamental skills in science especially in learning mathematics. The aim of this study is to identify teacher candidate's argument skills by posing mathematical sentences to further exposing them as mathematical arguments. It is a qualitative descriptive research. Data collection was done through written tests and in-depth interview. It involved 70 teacher candidates as the subjects. One of the subjects with distinguished test result was selected for further interview. The data were analyzed through data reduction. The findings revealed that teacher candidate's argument skills can be identified through an identification model. This model includes the identification of mathematical sentences, compilation of supporting data, modeling, mathematical model, interpretation, and determination of valid arguments.
\end{abstract}

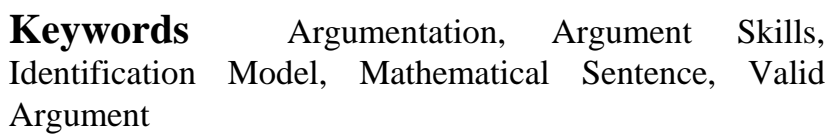

\section{Introduction}

Mathematical argument is a logical cognitive connection between and from mathematical statements. In mathematics, arguments are common in proving mathematical statements. In fact, a new theorem must go through a process to prove it as a solution for mathematical problems. Argumentation is often claimed as an activity that coincides with proof or justification. It is a basic skill in science and the most essential skill in learning mathematics (Indrawatiningsih, Purwanto, As'ari \& Dwiyana, 2019; Lubben et al., 2014; Indrawatiningsih, 2018; Chen, Lin, Chen, \& Chen, 2014; Stylianides \& Bieda, 2016). It includes one's skill in the process of making a statement along with evidence and logical reasons in order to justify, defend and promote particular beliefs, attitudes or values.

Argumentation can be claimed as a vital aspect that should be improved in the classroom in which students are encouraged to evaluate and pose questions in order to clarify and develop reasonable arguments (Krummheuer, 2007; Conner, Singletary, Smith, Wagner, \& Francisco, 2014a; Whitenack \& Knipping, 2002). Such skills entail the ability to compile valid arguments to obtain mutual agreement. Furthermore, in this process, students clarify and justify their solutions to solve problem equipped with assorted supporting evidence. Previous studies have shown that by engaging in argumentation, students will learn and make reflection easily in the learning process (Whitenack \& Knipping, 2002; Krummheuer, 2007; Krummheuer, 2013; Conner, Singletary, Smith, Wagner, \& Francisco, 2014b; Van Ness \& Maher, 2018; Wood, 2013).

In the present study, literature review has exposed various explanations related argument skills in mathematics regardless the absence of shared definition for this term. Nevertheless, a definition revealed by Chick and B. Mccra (2005) has been cited widely to represent this term (Chick \& Mccrae, 2005). They explained the skills as a process of preparing mathematical statements that are logically connected. The product or outcome of the process is called an argument (Chick \& Mccrae, 2005; Kaiser, 2013).

"The final sequence of statements accepted by all participants, which are more or less completely reconstructable by the participants or by an observer as well, will be called an argument”. The present study aimed at identifying the argument skills of mathematics teacher candidates. Two research questions (RQs) have been submitted to meet the research objectives of this study. They are as follows:

- $\quad$ First research question (RQ1): How to identify mathematics teacher candidate's argument from mathematical sentence? 
- $\quad$ Second research question (RQ2): How mathematics teacher candidates determine valid argument of a mathematical sentence?

In the context of this study, argument is referred as a collection of several premises and conclusions. Furthermore, it is presented as mathematical sentences - which later identified as valid arguments. The process of identifying mathematical sentences into a valid argument is done with an identification model. This model can be the basis for researchers, teachers and students for investigating mathematical argument skills. It is expected that the present study will contribute both theoretically and methodologically to the process of constructing a valid argument

\section{Materials and Methods}

\subsection{Design}

The present study is a qualitative descriptive study. Azwar (2017) explicated that descriptive study aims to analyze a problem and present facts in a systematic way. The present study describes a model for identifying mathematics candidate teacher's argument skills.

\subsection{Material}

Data used in the present study were obtained from written test and in-depth interview. The test contained mathematical sentences related to mathematical arguments. Meanwhile, in-depth interview was done to validate the data (Chick \& Mccrae, 2005; Creswell, 2012). In the present study, a model used to identify the elements of mathematical arguments was adopted from those of Toulmin (2003) and Krummheuer (1995).

\subsection{Research Subject}

The research subject involved 70 final semester students of a university in Pasuruan, East Java, Indonesia. Subsequently, one of them was selected as the subject in the interview with several considerations including: 1) the subject provided a correct answer, 2) the answer was distinctive or different from others in which the answer sheet contained handwritten additional answers with the potential of gaining new findings, and 3) the subject has good communication skills.

\subsection{Procedure}

The procedure of the study was initiated from the selection of 70 final semester students who are teacher candidates. Subsequently, problems related to mathematical arguments were distributed to the subjects. These problems were expressed in mathematical sentences that would be identified by the subjects. Of 70 subjects,
25 solved the problem correctly. However, one of them could provide a unique answer hence the subject was selected to be further interviewed in order to obtain the data validity. Subsequently, the data was analyzed.

The identified argument referred to the models developed (Brinkerhoff, 2007; Krummheuer, 2007; Knipping, 2002; Indrawatiningsih, Purwanto, As'ari \& Dwiyana, 2019; Mueller, 2009). Despite many studies have used the models, they have not explained how to distinguish arguments during the analysis process. Therefore, the present study used procedure to investigate mathematical argument skills in order to establish a model marked by connectors, i.e., "If", "then", "so", "in reality", and "in fact". This model has been carried out previously by (González, Herbst, \& Herbst, 2013).

\subsection{Data Collection Method}

The method used for identifying teacher candidate's argument skills was by analyzing the results of written tests (Lithner, 2008). It was followed up by an in-depth interview for the validity of data. Model proposed by Toulmin (2003) and Krummheuer (1995) was used to analyze the test result. The model is presented in Fig. 1.

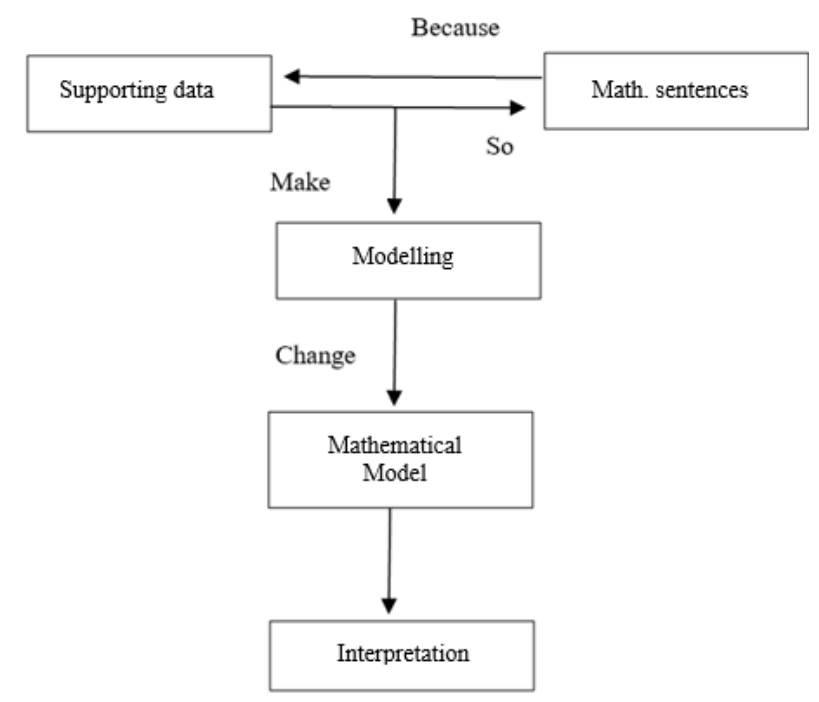

Figure 1. The argument model (modified)

In-depth interviews were carried out to obtain data validity. The researcher adopted a model from Toulmin (2003) and Krummheuer (1995) to analyze the results of written tests. The model can be seen in Figure 1.

Valid data is used to determine the framework for identifying mathematics teacher candidate's argument skills. In data analysis, several stages are carried out, namely: (1) data reduction with a focus on selecting the required main components and removing unnecessary ones; (2) data presentation is the stage of data analysis and grouping that has been reduced to two groups of: (a) the identification of the elements of argument, and (b) valid arguments; (3) conclusions about the findings and data presentation. 


\section{Result and Discussion}

Based on the results of tests conducted on 70 teacher candidates, 25 teacher candidates answered correctly that the given mathematical sentence is an argument. While 45 teacher candidates answered incorrectly, i.e. the mathematical sentence given is not an argument. Among the 25 teacher candidates who answered correctly then the researcher identified the stages by the teacher candidates in solving the problem to determine the mathematical sentence is a valid argument.

Table 1. Stages of Identification

\begin{tabular}{|c|c|c|}
\hline Stage & Code & $\begin{array}{c}\text { T Teacher } \\
\text { Candidate (\%) }\end{array}$ \\
\hline $\begin{array}{c}\text { Identification of Mathematical } \\
\text { Sentences which is an argument }\end{array}$ & A1 & 100 \\
\hline Provide Supporting Data & A2 & 60 \\
\hline Make a Mathematical model & A3 & 44 \\
\hline $\begin{array}{c}\text { Interpreting from Mathematical } \\
\text { Models }\end{array}$ & A4 & 24 \\
\hline Determine Valid Arguments & A5 & 4 \\
\hline
\end{tabular}

Stages are the sequence in solving problems. If prospective teachers arrive at stage A5 in solving problems, the teacher candidates also go through stages A1, A2, A3 and A4. From table 1 above shows that teacher candidates who did A1 as many as 25 people, A2 as many as 15 people, A3 as many as 11 people, A4 as many as 6 people and A5 as much as 1 person.

Figure 2 presents a summary of the percentage of the number of teacher candidates in identifying mathematical sentences as valid arguments. Stages by stages are sequentially identified so that the distribution of the teacher's ability to determine valid arguments can be known. The ability of teacher candidates to identify is based on the stages in completing test questions. The increasing stages in identifying mathematical sentences as valid arguments, the number of teacher candidates who meet these stages is increasingly low. Teacher Candidates who meet all stages in identifying mathematical sentences as valid arguments are $4 \%$. Therefore, in-depth interviews were conducted with teacher candidate who were able to complete the test questions using all stages of identification.

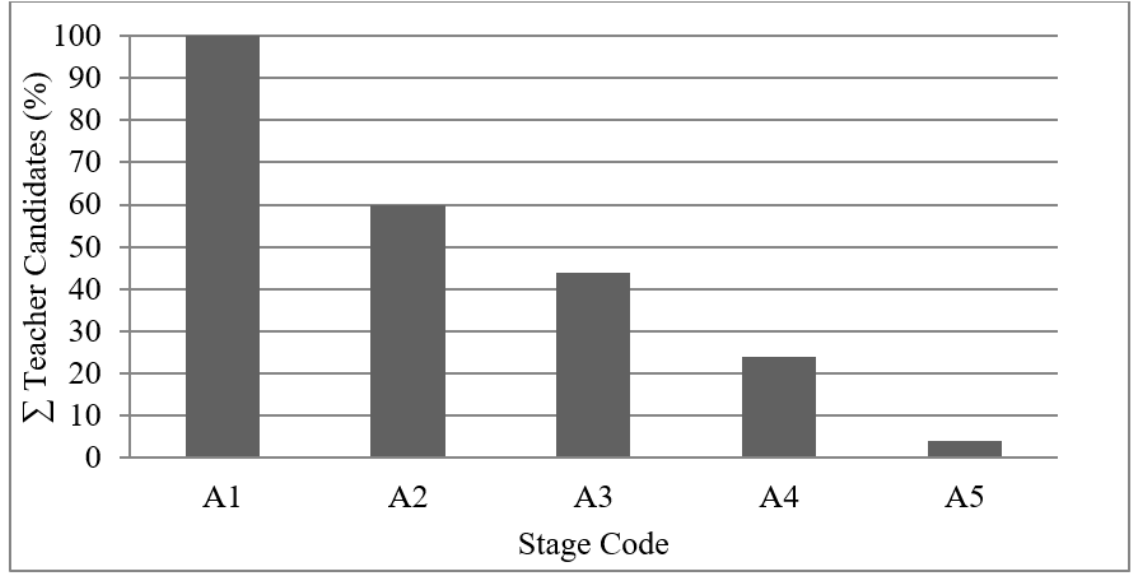

Figure 2. Percentage of stages of identification by teacher candidates

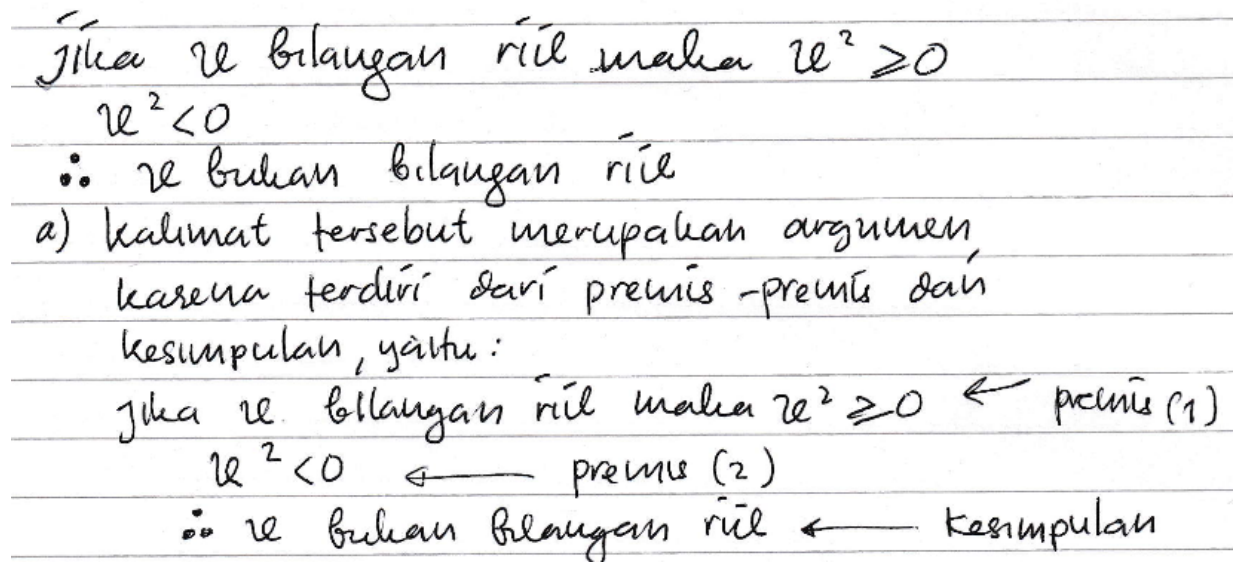

Figure 3. Teacher Candidate Work Results about Argument 
In the present study, mathematical sentences are presented in the form of statements accompanied by questions to answer. The teacher candidates were required to answer the questions. The measures carried out by the teacher candidate are clarified as follows:

First stage, the teacher candidate can identify the mathematical sentence as an argument because it consists of several premises and conclusions. It is indicated from the answer to the question as follows:

If $x$ is a real number so $x^{2} \geq 0$

$x^{2}<0$

$\therefore x$ is not a real number

The teacher candidate clarified that the mathematics sentence above is an argument since it consists of two premises and conclusion. Premise $1=$ If $x$ is a real number so $x^{2} \geq 0$, premise $2=$ If $x^{2}<0$, and it can be concluded that $x$ is not a real number. (Figure 3 )

The teacher candidate also clarified the answer related to the identification during interview session.

P: Why you identified mathematical sentence in the question as an argument?

S: I know it is an argument. It consists of two premises and conclusion.

$\mathrm{P}$ : Which one is a premise and which one is conclusion?

$\mathrm{S}$ : There are two premises in this question. The first is, if $x$ is a real number so $x^{2} \geq 0$. The second is $x^{2}<0$. The conclusion is that $x$ is not a real number.

P: Well, how do you identify a premise?

S: It is a statement used to draw a conclusion.

$\mathrm{P}$ : Are you sure that this mathematical sentence is an argument?

S: Yes, absolutely.

From the interview, it can be claimed that the teacher candidate has successfully identified an argument that consists of premises and conclusion.

Second stage, the teacher candidate provides supporting data to prove the accuracy of the answer. The answer is clarified by initially substituting the number into $x^{2} \geq 0$.
For example, $x=-1$ substituted into $x^{2} \geq 0$ so $(-1)^{2} \geq 0$ or $1 \geq 0$. When $x=0$, then $(0)^{2} \geq 0$ or $0 \geq 0$. When $x=1$, then $(1)^{2} \geq 0$ or $1 \geq 0$. Hence it can be summarized that the first premise $=$ If $x$ is a real number so $x^{2} \geq 0$ is true. The subject clarifies that none of real number fulfills $x^{2}<0$, thus it can be concluded that $x^{2}<0$ and $x$ is not a real number (Figure 4). The teacher candidate clarified the answer during the interview session.

The clarification given by the teacher candidate related to the supporting data is as follows:

P: Can you explain your handwriting answer in the answer sheet?

S: I actually want to give a proof that premises and conclusion in the argument within the question are correct.

P: How do you clarify it?

S: I did several measures, substitute the numbers into equation. Just like what I had written.

P: Can you explain more?

S: Of course (nodding)...I take $-1,0$, and 1 . Substitute them into equation of $x^{2} \geq 0$. When $x=-1$ is substituted to $x^{2} \geq 0$, the result is $1 \geq 0$, which is true. When $x=0$ is substituted to $x^{2} \geq 0$, the result is $0 \geq 0$, which is true. When $x=1$ is substituted to $x^{2} \geq 0$, the result is $1 \geq 0$, which is true. Thus, the first premise is proven. Nevertheless, it contradicts the fact of the second premise of $x^{2}<0$ as well as my understanding that none of real number fulfills the equation of $x^{2}<0$. Hence, it can be concluded that $x$ is not a real number.

P: Why did you take $-1,0$, and 1 as samples?

S: Well, I tried to pick negative, 0 , and positive numbers.

$\mathrm{P}$ : Why did you determine to take only three?

S: They are just examples. It is okay to have more examples.

Based on the interview, the subject provided supporting data in the form of an explanation in order to prove that the answer is correct.

\begin{tabular}{|c|}
\hline $1 \geqslant 0 \leftarrow$ Benar \\
\hline$r e=0 \longrightarrow(0)^{2} \geqslant 0+$ Pehar $\rho$ Behar \\
\hline$l e=1 \longrightarrow(1)^{2} \geqslant 0 \leftarrow$ Penar $]$ \\
\hline oz premis (2) \\
\hline$e^{2}<0$ msal $v=-1 \longrightarrow(-1)^{2}<0$ t salar \\
\hline $1 \quad x=0 \rightarrow(0)^{2}<0 e$ salas \\
\hline$x=1 \longrightarrow(1)^{2}<0 \leftrightarrow$ salas \\
\hline$\longrightarrow$ premis (2): $6^{2}<0 \rightleftarrows$ Bernilal Behar \\
\hline of Jas ve bulean blangan riel \\
\hline
\end{tabular}

Figure 4. Teacher Candidate Work Results about supporting data 


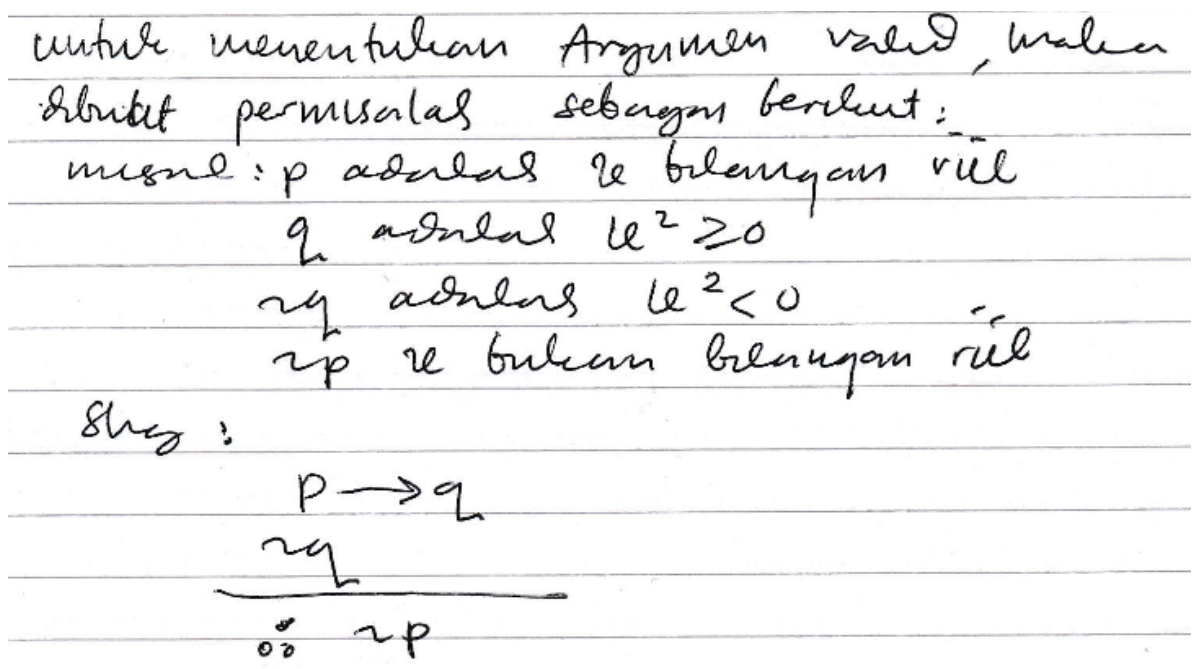

Figure 5. Teacher Candidate Work Results about modeling mathematical

Third stage, the teacher candidate modeled the mathematical sentence into an argument by using a modeling (Figure5).

Based on the question in the written test, the subject devised a mathematical model as follows:

If: $p$ is a real number $x$

$q$ is $x^{2} \geq 0$

$\sim q$ is $x^{2}<0$

$\sim p$ is not a real number $x$

So, it can be expressed:

$$
\begin{aligned}
& p \rightarrow q \\
& \therefore \sim q \\
& \sim p
\end{aligned}
$$

The teacher candidate clarified the answer related to the modeling of mathematical sentence as follows:

$P$ : You had a mathematical model in your answer. Why? Was there any reason?

S: I tried to modeling the argument within the question.

$P$ : What do you mean by modeling the argument?

$S$ : It is a mathematical model...just like what I had written in my answer...I used modeling, in this case $p$ is real number $x, q$ is $x^{2} \geq 0, \sim q$ is $x^{2}<0, \sim p$ is not real number $x$. Subsequently, I made the argument model namely,

$P:$ The mark of $\sim$, what is it?

S: It is negation or I call it the opposite. For example, $x=1$ then the negation/opposite is $x \neq 1$. Just like that...(Smiling).

P: Well...

The interview revealed that the teacher candidate was able to modeling mathematical arguments.

Fourth stage, the teacher candidate interprets the mathematical model that has been made and distinguishes between arguments and non-arguments. The subject clarified the explanation related to the interpretation as follows.
$P:$ In your opinion, what is the significance of modeling an argument?

$S:$ It can determine whether a mathematical sentence is an argument or not.

$P$ : Can you explain more about it?

S: It is used to distinguish between premise and conclusion.

P: If you have sorted them out, what is your next step?

S: I will be able to determine between arguments and non-arguments.

P: How do you distinguish them?

$S:$ An argument consists of premise and conclusion. The others consist of premises without any conclusion.

Fifth stage, the teacher candidate can distinguish between valid and invalid arguments (Figure 6). The subject claims that valid argument contains correct premises as well as correct conclusion. Even if only one of the premises is incorrect, the argument will be invalid, although the conclusion is correct. In addition, an argument is invalid if the premise is correct while the conclusion is incorrect.

The teacher candidate clarified the validity of an argument during the interview as follows:

$P$ : You argue that the argument in the question is valid, why?

S: It is valid because I have proven that all the premises and the conclusion are true (while showing the supporting data as the proof).

$P$ : So, how do you define a valid argument?

$S$ : An argument is valid if the premises are true and the conclusion is true. A single invalid premise leads to invalid argument even though the conclusion is correct. Meanwhile, if the conclusion is incorrect, the argument will be invalid too.

$P$ : Are you sure about it?

S: Certainly. 
Shy:

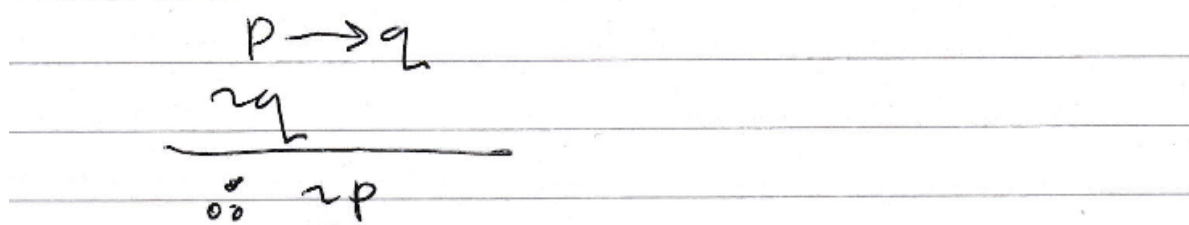

Jasi supat rsimpullean balimat matematien liatos merupaleon argumen Valio

Figure 6. Teacher Candidate Work Results about Valid Argument

If $x=-1$ substituted to $x^{2} \geq$ 0 so $(-1)^{2} \geq 0$ or $1 \geq 0$.

When $x=0$, then $(0)^{2} \geq 0$ or $0 \geq 0$. When $x=1$, then $(1)^{2} \geq 0$ or $1 \geq 0$.

None of real number fulfills $x^{2}<0$, thus $x$ is not a real number.
If $x$ is a real number so $x^{2} \geq 0$

$x^{2}<0$

$\therefore x$ is not a real number
Math. sentences

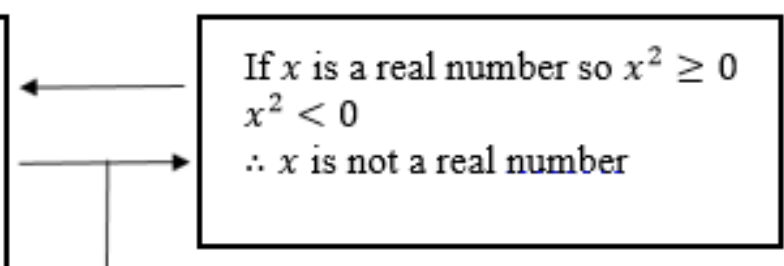

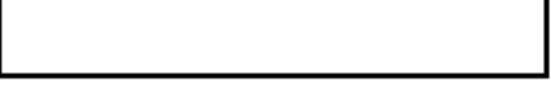

Suporting data

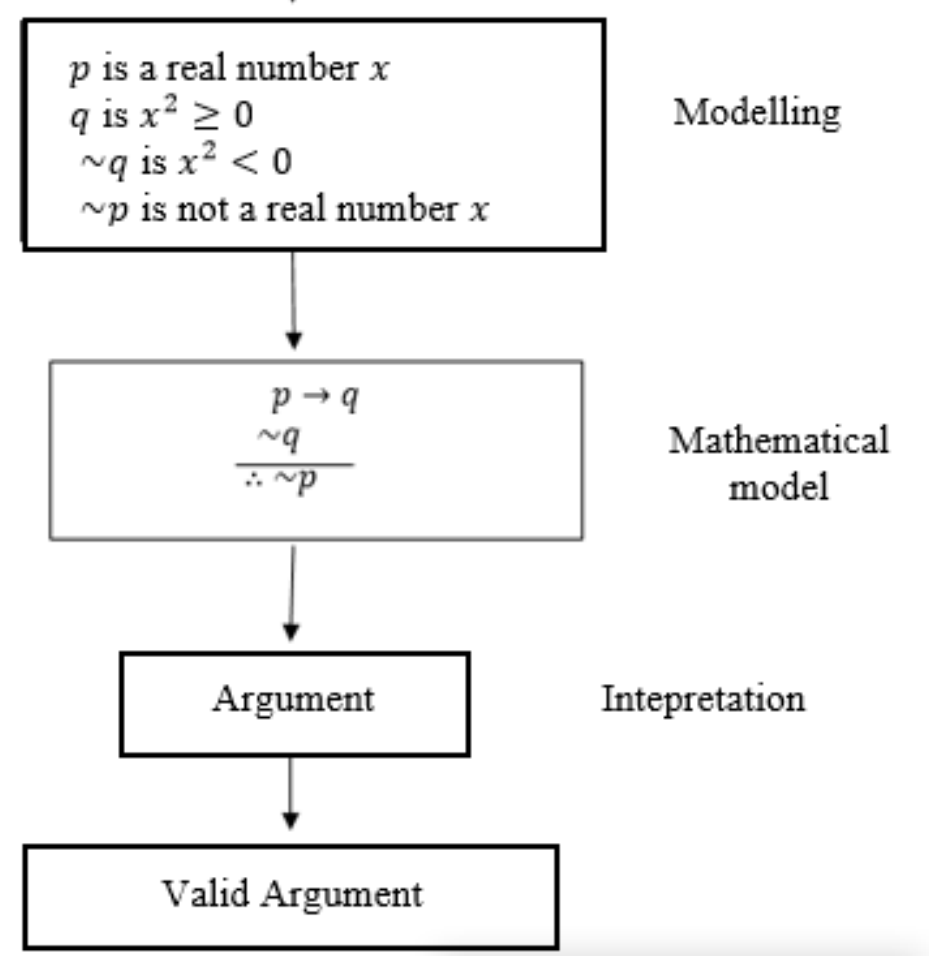

Figure 7. Identifcation model of valid argument 
Based on the measures taken by the teacher candidate in identifying mathematical sentences, it can be declared that the mathematical sentences are a valid argument as presented in Figure 7.

Conner et al., (2014) identified students' argument skills, identified the components of the argument through a tentative claim, and interpreted them in the form of data (Conner, Singletary, Smith, Wagner, \& Francisco, 2014). When identifying arguments, Conner et al., (2014) did not necessarily include warrants, which contradicted the research carried out by Nordin \& Boistrup (2018) - which showed the necessity of warrant despite of its implicitly disclosure (Nordin \& Björklund Boistrup, 2018). In the present study, the teacher candidates as the subject initially identified the mathematical sentences and later looked for supporting data to prove the validity of the sentences. The mathematical sentences intended in this study were a number of premises and conclusions. Previous studies have disclosed the existence of warrant both implicitly and explicitly. Meanwhile, the present stud involved no warrant but mathematical modeling. Such modeling was used to form a mathematical model (Figure 5). Furthermore, the mathematical model is interpreted as a valid or invalid argument.

The identification model carried out in the present study provides a mathematical justification according to the presentation in the form of mathematical sentences (Figure 7.). It has been done previously by Lithner (2008). Nevertheless, despite many studies have discussed mathematical arguments, not all of them express the argument by using connectors, i.e., "even though", "and then", "but", and "because," as carried out by González and Herbst (2013). In the present study, the analytical framework begins with mathematical sentences with conjunctions of "if", "then" and "so". Subsequently, it is modeled in the form of a mathematical model, which later can be identified as a valid or invalid argument.

\section{Conclusions}

Based on the findings, it can be concluded that the argument skills of a teacher candidate can be identified through the identification model. The model is summarized as follows:

a. Identification of mathematical arguments through mathematical sentences. Teacher candidate is able to identify argument in a mathematical sentence. Teacher candidate concludes that the argument consists of several premises and conclusions.

b. Compilation of supporting data to prove mathematical arguments. Teacher candidate provides supporting data to reaffirm the mathematical sentence is true.

c. Modeling. Teacher candidate carries out modeling to change mathematical sentence into a mathematical model. Furthermore, the outcome of modeling the sentence is expressed into a model.

d. Interpretation. The identified mathematical arguments are interpreted. Based on the mathematical model, teacher candidate is able to interpret a mathematical sentence as a mathematical argument.

e. Determination of a valid/invalid argument. Teacher candidate is able to determine a mathematical sentence is an argument and the argument is valid. Teacher candidate explains that each premise and conclusion in the argument is all true thus the argument is valid.

\section{Acknowledgements}

The researchers would like to express their gratitude to the Indonesian Endowment Fund for Education (LPDP), the Graduate Program of Mathematics Education at The State University of Malang, and STKIP PGRI Pasuruan

\section{REFERENCES}

[1] Brinkerhoff, J. A. (2007). Applying Toulmin' s Argumentation Framework to Explanations in a Reform Oriented Mathematics Class.

[2] Chen, Y., Lin, J., Chen, Y., \& Chen, Y. (2014). Science Activities : Classroom Projects and Curriculum Students in Argument : Using Density as an Example Teaching Scienti fi c Core Ideas through Immersing Students in Argument : Using Density as an Example, (June), 37-41. https://doi.or $\mathrm{g} / 10.1080 / 00368121.2014 .915792$

[3] Chick, H., \& Mccrae, B. (2005). ARGUMENTATION PROFILE CHARTS AS TOOLS FOR ANALYSING STUDENTS ’ ARGUMENTATIONS, 4, 281-288.

[4] Conner, A. M., Singletary, L. M., Smith, R. C., Wagner, P. A., \& Francisco, R. T. (2014a). Identifying Kinds of Reasoning in Collective Argumentation. Mathematical Thinking and Learning, 16(3), 181-200. https://doi.org/10. 1080/10986065.2014.921131

[5] Conner, A. M., Singletary, L. M., Smith, R. C., Wagner, P. A., \& Francisco, R. T. (2014b). Teacher support for collective argumentation: A framework for examining how teachers support students' engagement in mathematical activities. Educational Studies in Mathematics, 86(3), 401429. https://doi.org/10.1007/s10649-014-9532-8

[6] Conner, A., Singletary, L. M., Smith, R. C., Wagner, A., \& Francisco, R. T. (2014). Mathematical Thinking and Learning Identifying Kinds of Reasoning in Collective Argumentation Identifying Kinds of Reasoning in Collective Argumentation. Mathematical Thinking and Learning, (September 2014), 37-41. https://doi.org/10.108 0/10986065.2014.921131

[7] Creswell, J. (2012). Educational Research. Pearson 
Education, Inc., 501 Boylston Street, Boston, MA 02116.

[8] González, G., Herbst, P., \& Herbst, P. (2013). An Oral Proof in a Geometry Class : How Linguistic Tools Can Help Map the Content of a Proof An Oral Proof in a Geometry Class : How Linguistic Tools Can Help Map the Content of a Proof, (October 2014), 37-41. https://doi.org/10.1080/07370008. 2013.799166

[9] Indrawatiningsih, N. (2018). Arguments in Critical Thinking Ability, 218(ICoMSE 2017), 12-15.

[10] Kaiser, G. (2013). Competency of Prospective Chinese Mathematics Teachers on Mathematical Argumentation and Proof, 15(1), 81-97.

[11] Knipping, C. (n.d.). THE SOCIAL DIMENSION OF ARGUMENTATION AND PROOF IN MATHEMATICS CLASSROOMS.

[12] Krummheuer, G. (2007). Argumentation and participation in the primary mathematics classroom. Two episodes and related theoretical abductions. Journal of Mathematical Behavior, 26(1), 60-82. https://doi.org/10.1016/j.jmathb.2 007.02.001

[13] Krummheuer, G. (2013). The relationship between diagrammatic argumentation and narrative argumentation in the context of the development of mathematical thinking in the early years. Educational Studies in Mathematics, 84(2), 249-265. https://doi.org/10.1007/s10649-013-94719

[14] Lin, S. (2013). Science and non-science undergraduate students ' critical thinking and argumentation performance in reading a science news report, (September).

[15] Lithner, J. (2008). A research framework for creative and imitative reasoning. Educ Stud Math, 67(3), 255-276. https://doi.org/10.1007/sl0649-007-9104-2

[16] Lubben, F., Sadeck, M., Scholtz, Z., Braund, M., Lubben, F., Sadeck, M., \& Scholtz, Z. (2014). Gauging Students' Untutored Ability in Argumentation about Experimental Data: A South African case study Gauging Students' Untutored Ability in Argumentation about Experimental Data : A South African case study, 37-41. https://doi.org/1 $0.1080 / 09500690903331886$

[17] Mueller, M. F. (2009). The Journal of Mathematical Behavior The co-construction of arguments by middle-school students, 28, 138-149. https://doi.org/10.10 16/j.jmathb.2009.06.003

[18] Indrawatiningsih, Purwanto, A. R. As'ari, \& Dwiyana. (2019). The ability of high school students ' critical thinking in solving trigonometric problems $\mathrm{T}$ he ability of high school students ' critical thinking in solving trigonometric problems. IOP Conf. Series: Earth and Environmental Science 243 (2019) 012050. https://doi.org/10.1088/1755$1315 / 243 / 1 / 012050$

[19] Nordin, A. K., \& Björklund Boistrup, L. (2018). A framework for identifying mathematical arguments as supported claims created in day-to-day classroom interactions. Journal of Mathematical Behavior, (June), 113. https://doi.org/10.1016/j.jmathb.2018.06.005

[20] Stylianides, A. J., \& Bieda, K. N. (2016). 9. Proof and Argumentation in Mathematics Education Research, (Icmi),
315-351.

[21] Van Ness, C. K., \& Maher, C. A. (2018). Analysis of the argumentation of nine-year-olds engaged in discourse about comparing fraction models. Journal of Mathematical Behavior, (January), 0-1. https://doi.org/10.1016/j.jmathb. 2018.04.004

[22] Whitenack, J. W., \& Knipping, N. (2002). Argumentation, instructional design theory and students' mathematical learning: A case for coordinating interpretive lenses. Journal of Mathematical Behavior, 21(4), 441-457. https://doi.org/10.1016/S0732-3123(02)00144-X

[23] Wood, T. (2013). Creating a Context for Argument in Mathematics Class, 30(2), 171-191. 